\title{
Evaluasi Pelaksanaan Sistem Identifikasi Pasien di Instalasi Rawat Inap Rumah Sakit
}

\section{Evaluation on Patient Identification System Implementationin Hospital's Inpatient Unit}

\author{
Dewi Anggraeni ${ }^{1}$, Lukman Hakim², Cecilia Widjiati $I^{3}$ \\ ${ }^{1}$ Rumah Sakit Tentara Tk. II dr. Soepraoen Malang \\ ${ }^{2}$ Program Studi Magister Manajemen Rumah Sakit Fakultas Kedokteran Universitas Brawijaya Malang \\ ${ }^{3}$ Rumah Sakit Panti Nirmala Malang
}

\begin{abstract}
ABSTRAK
Keamanan pelayanan di rumah sakit dimulai dari ketepatan identifikasi pasien. Rumah sakit harus membangun sistem yang menjamin bahwa pelayanan yang tepat diberikan kepada pasien yang tepat. Kajian ini bertujuan untuk mengetahui penyebab belum optimalnya pelaksanaan sistem identifikasi pasien serta mencari alternatif solusi untuk mengoptimalkan pelaksanaan sistem identifikasi pasien di Ruang Rawat Inap RS.X Malang. Penelitian ini merupakan studi kasus dengan pendekatan kualitatif. Metode pengumpulan data dilakukan dengan focus group discussion (FGD), wawancara, pengamatan serta studi dokumen. Identifikasi prioritas alternatif solusi menggunakan brainstorming dengan mempertimbangkan urgency, severity/seriousness, growth (USG). Secara struktur sistem identifikasi pasien cukup lengkap. Pengetahuan perawat tentang sistem identifikasi pasien cukup baik. Sikap perawat dan petugas lain terhadap pelaksanaan prosedur identifikasi pasien adalah positif namun tidak selalu melakukan prosedur verifikasi sesuai ketentuan terutama untuk tindakan yang menurut perawat tidak berisiko terutama pada saat shift sore dan malam. Keterbukaan untuk melaporkan insiden pada petugas masih belum optimal. Kendala dan hambatan terutama dirasakan masih sulit merubah kebiasaan untuk selalu melakukan verifikasi, terkadang pasien mengeluh jika terlalu sering ditanya identitasnya, tidak dirasakan adanya kendala ketersediaan gelang identitas, kadang-kadang terjadi salah cetak nama pada stiker identitas. Penyebab utama belum optimalnya pelaksanaan sistem identifikasi pasien berhubungan dengan sistem supervisi terhadap pelaksanaan prosedur identifikasi yang belum optimal serta budaya safety yang masih perlu terus ditingkatkan.
\end{abstract}

Kata Kunci: Budaya keselamatan pasien, keselamatan pasien, sistem identifikasi pasien

\begin{abstract}
Security of services in the hospital starts from the patient identification accuracy. Hospitals must establish a system which ensures that proper care is given to the right patient. This study aims to determine the causes of non-optimal implementation of patient identification system as well as finding alternative solutions to optimize the implementation of patient identification systems in Inpatient units of " $X$ " hospital in Malang. This research is a case study with qualitative descriptive approach. Data collection methods were using Focus Group discussion (FGD), interviews, observations and document studies. Identification of alternative solution priority was using brainstorming by considering Urgency, Severity/Seriousness, and Growth (USG). Structurally, patient identification system is quiet adequate. Nurses' knowledge about patient identification system is quite good. Nurses/other personnel attitude on the implementation of patient identification procedure is positive but do not always perform verification procedure for no risk action especially by the nurses during the evening and night shifts. Openness to incident reporting to the personnel is still not optimal. Constraints/barriers perceived were that it is still difficult to change the habit to always perform the verification, patients sometimes complain if their identity is asked too frequently, identity bracelet availability is not an issue, name misprint on the sticker identity sometimes happens. The main cause of non-optimal implementation of patient identification system is related to not optimal supervision system of the implementation of the identification procedure and safety culture that still needs to be improved.
\end{abstract}

Keywords: Hospital accreditation, patient identification system, patient safety

Jurnal Kedokteran Brawijaya, Vol. 28, Suplemen No. 1 2014: Dewi Anggraeni. Rumah Sakit Tentara Tk. II dr. Soepraoen Malang, Jl. Sudanco Supriadi No. 22 Malang Tel. (0341) 325111 Email: anggraenidewi57@yahoo.co.id 


\section{PENDAHULUAN}

Perkembangan ilmu pengetahuan dan teknologi di bidang kesehatan, pada satu sisi dapat menjawab tuntutan kebutuhan pelayanan kesehatan yang semakin komplek. Disisi lain perkembangan teknologi juga dapat memunculkan masalah baru yaitu risiko yang timbul sebagai dampak pemanfaatannya jika penerapannya tidak berada pada sistem yang aman. Hal ini menyebabkan pelayanan kesehatan selalu dibayangbayangi oleh risiko terjadinya kesalahan atau ketidaktepatan pelayanan yang bisa berdampak merugikan bagi pasien, tenaga kesehatan sendiri maupun institusi penyelenggara pelayanan kesehatan. Rumah Sakit harus mampu memberikan perlindungan terhadap keselamatan pasien, masyarakat, lingkungan rumah sakit, serta sumber daya manusia yang ada. Paradigma baru dalam sistem akreditasi KARS versi 2012, mengarahkan seluruh kegiatan pelayanan rumah sakit agar mampu memberikan pelayanan yang memenuhi standar kualitas serta jaminan rasa aman dan perlindungan terhadap dampak pelayanan yang diberikan dalam rangka pemenuhan hak-hak masyarakat akan pelayanan yang berkualitas serta aman (1).

Keamanan pelayanan di rumah sakit salah satunya dimulai dari ketepatan identifikasi pasien (2). Kesalahan identifikasi pasien diawal pelayanan akan berdampak pada kesalahan pelayanan pada tahap selanjutnya (2).
Rumah sakit harus menjamin proses identifikasi ini berjalan dengan benar sejak pertama kali pasien didaftar (3). Risiko keselamatan terjadi ketika terdapat ketidak cocokan antara pasien dengan item pelayanan yang seharusnya diterima, baik bersifat diagnostik, terapeutik maupun pelayanan pendukung lainnya (4). Kesalahan identifikasi pasien merupakan akar masalah adanya banyak kesalahan yang terjadi (2). Lembaga Nasional Keselamatan Pasien Inggris melaporkan 236 kejadian near miss berhubungan dengan kehilangan gelang identitas dan informasi yang salah pada gelang identitas selama November 2003 sampai Juli 2005 (6). Kesalahan identifikasi juga ditemukan pada lebih dari 100 analisa akar masalah pada Januari 2000 sampai maret 2003 oleh United States Departement of Veterans Affairs (VA) National Center for Patient Safety (5). NSQHS Australia mencatat adanya 10 kejadian akibat kesalahan pasien atau anggota badan yang salah yang berdampak kematian atau kehilangan fungsi secara permanen selama tahun 20092010 dan diperkirakan bisa naik jika kasus-kasus kesalahan identifikasi pada lingkup non bedah (patologi dan radiologi) masuk kedalam data yang dilaporkan (4).

Data insiden keselamatan pasien di Rumah Sakit tempat studi paska akreditasi pada periode bulan Januari sampai dengan September 2013 tercatat sebanyak 76 insiden yang terdiri dari Kejadian tidak diharapkan/KTD (8\%), kejadian nyaris cedera/KNC (1\%) serta kejadian Tidak Cedera/KTC (91\%). Dari 76 insiden yang dilaporkan tersebut, 10 insiden

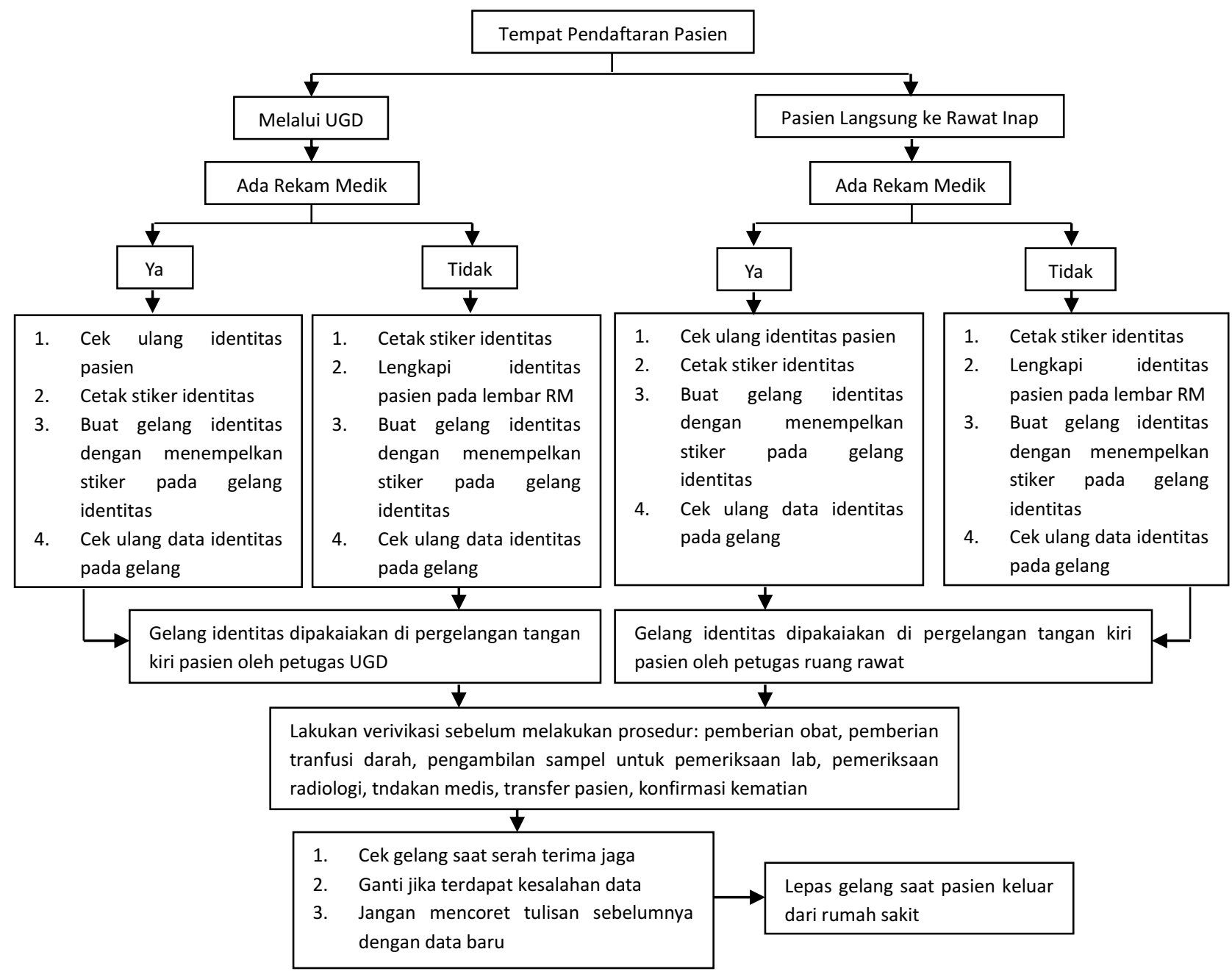

Gambar 1. Alur pelaksanaan identifikasi pasien 
keselamatan pasien pada bulan Pebruari sampai dengan Juni2013menemukanadanyakesalahanidentifikasipasien sebanyak 89 kali dengan rerata 18 kali per bulan. Hal ini menunjukkan bahwa sistem identifikasi di rumah sakit ini belum berjalan optimal, meskipun rumah sakit telah terakreditasi. Kajian ini dilakukan untuk mengeksplorasi penyebab belum optimalnya penerapan sistem identifikasi pasiendanmengembangkanalternativesolusi.

\section{METODE}

Gambaran implementasi dan hambatan pelaksanaan sistem identifikasi pasien diperoleh melalui wawancara mendalam dengan dua orang anggota Tim Mutu dan staf Bidang Perawatan serta dua orang perawat pelaksana dan dua orang perawat manajer. Selain itu dilakukan focus group discussion (FGD) dengan dua kelompok perawat manajer dan perawat pelaksana yang masing-masing diikuti oleh 7 orang kepala ruang dan perawat supervisi serta 11 perawat pelaksana. Fokus pengamatan adalah pada variabel pengetahuan perawat tentang sistem identifikasi, sikap perawat dan petugas lain dalam melaksanakan prosedur identifikasi pasien, kendala atau hambatan dalam melaksanakan prosedur identifikasi pasien serta pelaksanaan pengawasan kepatuhan staf terhadap prosedur identifikasi pasien. Identifikasi alternatif solusi diperoleh melalui brainstorming bersama tim mutu dan staf Bidang Perawatan dengan mempertimbangkan faktor urgency, severity/seriousness, growth(USG).

\section{HASIL}

\section{Gambaran Sistem Identifikasi Pasien}

Pelaksanaan identifikasi pasien dimulai sejak di tempat pendaftaranpasien(TPP). Identitas dicetakpadastikeryang selanjutnyaakan ditempelkan padagelangidentitaspasien dan formulir permintaan pemeriksaan penunjang. Identitas pasien yang tertera di stiker terdiri dari empat identitas yang meliputi nama, alamat, tanggal lahir dan no rekam medis pasien. Identitas yang dimaksud 100 harus berdasarkan bukti kartu identitas pasien. Pelaksanaan sistem identifikasi di rumah sakit tempat studi disajikan pada Gambar1.

Gelang identitas dibedakan dengan kriteria sebagai berikut: gelang berwarna merah muda digunakan pada pasien wanita, gelang warna biru digunakan pada pasien laki-laki, gelang warna putih untuk bayi baru lahir yang belum jelas atau belum dapat dipastikan jenis kelaminnya, kancing warna merah sebagai tanda alergi terhadap suatu obat atau bahan makanan tertentu, kancing warna kuning untuk penanda pada pasien yang memiliki risiko jatuh, kancing ungu untuk pasien 'do not resuscitate' (DNR) dan stiker berwarna coklat untuk pasien dengan nama sama dan dirawat diruang yang sama.

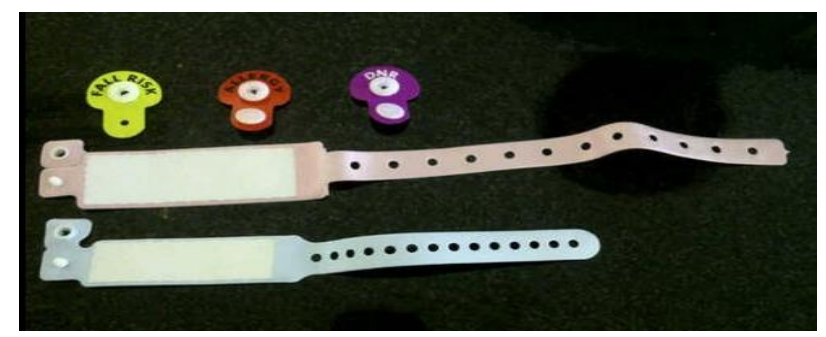

Gambar 2. Gelang dan kancing identitas pasien
Pemasangan gelang identitas dilaksanakan oleh petugas ruang rawat inap atau petugas IGD. Data pada gelang harus diverifikasi setiap akan melakukan tindakan pemberian obat, pemberian tranfusi darah, pengambilan sampel untuk pemeriksaan laborat, pemeriksaan radiologi, tindakan kedokteran, transfer pasien serta pada saat dilakukan konfirmasi kematian. Pelaksanaan verifikasi dilakukan dengan menanyakan nama dan tanggal lahir jika pasien jelas tahu nama dan tanggal lahir, atau nama dan alamat jika pasien tidak mengetahui tanggal lahir. Pelaksanaan verifikasi identitas dilakukan oleh petugas kepada pasien jika pasien dalam keadaan sadar dan berada dalam kapasitas mampu menjawab pertanyaan dengan benar, kepada keluarga jika kondisi pasien tidak memungkinkan atau pada pasien bayi sampai balita, atau oleh petugas kepada petugas lain jika pasien merupakan pasien yang mendapat perawatan intensif dengan mencocokkan dengan gelang pasien. Konfirmasi kematian dilakukan bersama dengan keluarga terdekat pasien yang meninggal. Pemasangan kancing tanda alergi dilakukan oleh petugas yang pertama kali mengidentifikasi adanya alergi terhadap obat atau bahan makanan tertentu. Pemasangan kancing warna kuning tanda pasien berisiko jatuh dipasang $1 \times 24$ jam setelah dilakukan identifikasi risiko. Pemasangan kancing penanda 'tidak boleh dilakukan resusitasi' (DNR) dilakukan setelah terdapat keputusan 'tidak boleh dilakukan resusitasi' pada pasien. Pemasangan gelang penanda pada bayi yang belum jelas identitas jenis kelaminnya dilakukan setelah bayi lahir dan dinyatakan tidak jelas diketahui jenis kelaminnya laki-laki atau perempuan. Pemasangan stiker warna coklat dilakukan pada pasien yang memiliki nama sama dan dirawat diruang yang sama.

Konfirmasi kematian dilaksanakan oleh petugas pada saat serah terima jenasah dengan keluarga. Pelepasan gelang identitas dilakukan saat pasien pulang atau keluar dari rumah sakit setelah semua proses pemberian obat dan penjelasan tentang rencana perawatan selanjutnya selesai dilakukan. Kondisi yang membolehkan pelepasan gelang misal jika pemasangan gelang mengganggu pelaksanaan prosedur tindakan sehingga gelang dilepas pada saat melakukan prosedur tindakan dan dipasang kembali setelah prosedur tindakan selesai dilaksanakan. Sebelum gelang dipasangkan pada pasien, perawat wajib memberikan penjelasan terlebih dahulu tentang tujuan prosedur itu dilakukan, serta kapan perawat akan melakukan verifikasi. Jika pasien terjadi reaksi alergi akibat pemakaian gelang identitas, maka bisa dilapisi dengan kasa saat memasangkan atau dengan memasangkan (menempelkan) gelang di baju pasien.

\section{Pelaksanaan Sistem Identifikasi Pasien}

Berdasarkan hasil FGD, pada umumnya perawat memiliki pengetahuan dan pemahaman yang baik tentang sistem identifikasi pasien yang ditunjukkan dalam kutipan komentar saat FGD. Perawat memahami bahwa tujuannya adalah mencegah kesalahan identitas yang dapat menyebabkan kesalahan tindakan, demi keamanan petugas. Perawat juga menyadari bahwa petugas tidak selalu hafal dengan identitas pasien.

Pp 1: “ .....adalah cara untuk mengidentifikasi pasien agar tidak salah pasien waktu melakukan tindakan....pakai gelang identitas, kalau perempuan pakai gelang merah, kalau laki-laki pakai gelang biru...pakai nama, alamat, tanggal lahir" 
Pp2: “......yaaa...tujuannya supaya tidak salah pasien waktu melakukan tindakan....supaya tindakan kita amanlah..."

Pp3: “.....pasien kan banyak, kadang kita juga gak hafal satu-satu, kalau tidak diidentifikasi dulu khuatirnya nanti salah....."

Perawat juga mempunyai sikap positif terhadap pelaksanaan sistem identifikasi karena menyadari pentingnya ketepatan identifikasi. Disamping untuk keamanan pasien, perawat menyadari ketepatan identifikasi juga merupakan bentuk perlindungan pada petugas karena semakin meningkatnya kesadaran hukum masyarakat.

Pp1: ".....saya setuju sekali...kan untuk keamanan pasien...."

Pp2: “....untuk melindungi kita juga sih.....supaya gak salah....sekarang kan pasien sudah pinter-pinter, gampang sekali menuntut kalau sampai terjadi kesalahan....."

Dalam pelaksanaannya, perawat tidak selalu melakukan verifikasi saat akan melakukan tindakan keperawatan. Hal itu terutama terjadi pada saat melakukan tindakan keperawatan yang bersifat rutin yang menurut mereka tidak akan menimbulkan risiko bagi pasien dengan alasan merasa sudah hafal dengan pasien, sibuk atau tidak sempat serta menghindari kebosanan pasien jika terlalu sering diminta untuk menyebutkan identitasnya. Tetapi pada saat memberikan obat kepada pasien, memberikan produk darah (tranfusi) atau mengambil sampel pemeriksaan laboratorium selalu diawali dengan verifikasi terlebih dahulu.

Pp1: “.... Gak mesti.....kalau pas repot ya gak sempat,.....kita sudah hafal sama pasiennya...."

Pp2: “.....ya mesti, kalau mau nyuntik mesti verifikasi dulu, mau tranfusi juga, mau bagi obat......mau ambil sampel darah....."

Pp3: “.....Kadang-kadang pasien yang keberatan.....kok bolak-balik ditanya to sus??....... tapi biasanya ya terus dijelaskan tujuannya apa....."

Dalam melaksanakan tindakan medis, dokter biasanya jarang melakukan verifikasi pasien, proses verifikasi dilakukan oleh perawat sebelum tindakan medis dilakukan. Pelaksanaan prosedur verifikasi pasien oleh petugas gizi, petugas laborat serta petugas radiologi pada umumnya selalu dilaksanakan.

Pp1:"......Gak pernah, paling ya kita perawatnya yang melakukan verifikasi...."

Pm1:"....Memang sulit kalau sama dokternya, biasanya ya perawatnya yang verifikasi....."

Dari gambaran diatas dapat diambil kesimpulan bahwa kepatuhan perawat dalam melaksanakan prosedur identifikasi cukup baik meskipun tidak sepenuhnya patuh. Beberapa kendala yang disampaikan diantaranya jika sedang sibuk prosedur identifikasi tidak dilakukan atau tidak sempat dilaksanakan. Pasien mengeluh jika terlalu sering ditanya identitasnya. Petugas juga masih merasakan sulit merubah kebiasaan untuk selalu melakukan prosedur identifikasi (verifikasi). Dari sisi teknis terkadang masih ditemukan data identitas dicetak tidak sesuai dengan bukti identitas yang dimiliki pasien atau terjadi kesalahan cetak.
Pelaksanaan supervisi terhadap pelaksanaan prosedur identifikasi pada shift pagi dirasakan cukup. Meskipun demikian pada shift sore dan malam fungsi supervisi ini dirasakan kurang, sehingga proses identifikasi sering tidak dilakukan. Selain itu terdapat sebagian petugas yang berpendapat bahwa mengawasi kepatuhan staf bukan merupakan bagian dari tugas dan fungsi supervisi.

Pm 1:"... Kalau shift pagi ada Tim Mutu yang selalu keliling ke ruangan-ruangan dan terlibat langsung dalam pelayanan ....... ada staf yang tidak melakukan ..... langsung di koreksi dan diingatkan....."

Pm 2:".....Tugas mengawasi kepatuhan staf ........ tidak masuk dalam uraian tugas perawat supervisi....."

Perawat tidak selalu mencatat dan melaporkan adanya kesalahan identifikasi atau ketidaktepatan pelaksanaan prosedur identifikasi. Kesalahan yang paling sering ditemukan adalah kekeliruan ejaan penulisan nama. Keengganan melaporkan disebabkan masih ada rasa tidak enak atau sungkan melaporkan secara tertulis jika terdapat teman atau petugas lain yang tidak melaksanakan prosedur identifikasi dengan benar. Perawat juga menyatakan bahwa jika dirinya yang dilaporkan juga belum bisa menerima.

Pp 1:"... Gak enak melaporkan temen sendiri......"

Pp2:"....Saya sendiri kalo dilaporkan paling ya nggrundel......"

Pm1:"....Sudah diberi pelatihan tentang pelaporan insiden.....tapi ya masih sungkan, rasa gak enak masih ada......"

Pm2: "....Yang sering salah ejaan dalam nama........"

\section{DISKUSI}

Pada lingkup pelayanan kesehatan, dimana banyak melibatkan kerja tim, peralatan serta prosedur yang banyak dan bervariasi dalam hal tingkat kompleksitasnya (6), maka untuk mencegah terjadinya kesalahan, sangat perlu dibangun sistem yang mendukung orang untuk tidak berbuat salah dan mendorong orang untuk berbuat benar (7). Perbaikan sistem saja tidak cukup karena sering kali peran manusia (human errors) dalam terjadinya kesalahan sangat menentukan, sehingga diperlukan pendekatan budaya dalam berbagai kasus untuk mengontrol terjadinya kejadian yang tidak diharapkan (7).

Dalam mewujudkan pelayanan yang beorientasi pada keselamatan pasien, rumah sakit X melaksanakan melalui dua pendekatan. Pendekatan pertama adalah pendekatan sistem (hard approach) dengan pelaksanaan Akreditasi versi $2012 / \mathrm{JCl}$ yang telah dilakukan melalui penataan struktur dengan penyusunan kebijakan, pedoman, panduan serta prosedur operasional sesuai dengan standar yang telah ditetapkan sampai kepada evaluasi terhadap pelaksanaannya. Sistem evaluasi dan pengawasan bagi staf keperawatan melalui edukasi dan supervisi yang dilakukan oleh perawat manajer (kepala ruang) dan tim mutu rumah sakit dirasakan baru efektif pada staf yang berada pada shift pagi, sedangkan pada shift sore dan malam hari, fungsi pengawasan kurang berjalan optimal. Hal ini disebabkan karena tugas perawat supervisi yang merupakan wakil Bidang Keperawatan di luar jam dinas belum mencakup pengawasan terhadap kepatuhan staf dalam melaksanakan prosedur. Beberapa penelitian telah membuktikan bahwa peran supervisi 
sangat kuat dalam mendorong melalui bimbingan dan arahan yang diberikan kepada staf keperawatan agar pelaksanaan pelayanan perawatan yang lebih berkualitas (8-10).

Supervisi mempunyai pengertian segala bantuan dari pemimpin atau penanggung jawab keperawatan yang bertujuan untuk pengembangan perawat dan staf lain dalam mencapai tujuan asuhan keperawatan. Kegiatan supervisi berupa dorongan, bimbingan dan kesempatan untuk pertumbuhan keahlian dan ketrampilan perawat. Agar dapat menjalankan tugas dan fungsinya dengan baik, seorang supervisor harus memenuhi kompetensi dalam hal memberikan pengarahan dan petunjuk yang jelas, memberikan saran, nasehat dan bantuan kepada staf dan pelaksana keperawatan. Seorang supervisor harus mampu memberikan motivasi untuk meningkatkan semangat kerja staf dan pelaksana keperawatan, proses kelompok, memberi latihan dan bimbingan yang diperlukan staf, melakukan penilaian terhadap penampilan kerja perawat serta mengadakan pengawasan agar pelayanan keperawatan lebih baik. Melalui supervisi, SDM keperawatan akan mempertahankan kemampuan dan perilaku dalam melaksanakan asuhan keperawatan sehingga kualitas asuhan yang diterima klien selalu sama pada setiap orang.

Pendekatan kedua yang dilakukan oleh rumah sakit adalah melalui pendekatan budaya (soft approach) melalui internalisasi nilai-nilai keselamatan pasien kepada seluruh staf. Upaya yang telah dilakukan rumah sakit adalah melalui pengenalan materi yang terkait dengan keselamatan pasien kedalam orientasi bagi karyawan baru serta materi diklat pengembangan staf baik melalui inhouse maupun exhousetraining. Penanaman nilai-nilai budaya safety dapat dilakukan dengan cara (7): Sosialisasi (formal atau informal misalnya saat pertemuan yang rutin diadakan, saat kunjungan kepada karyawan oleh pimpinan), pemasangan simbol, slogan serta poster yang berhubungan dengan program keselamatan pasien, pelatihan (untuk perubahan pengetahuan (kognitif), sikap (afektif), perilaku (psikomotorik), organisational learning, kegiatan ini dilakukan oleh tim inti dengan cara melakukan evaluasi terhadap hasil RCA, evaluasi program serta evaluasi terhadap upaya sosialisasi untuk menentukan langkah-langkah perbaikan. Keteladanan para pemimpin dalam bentuk perilaku sehari-hari yang menggambarkan budaya safety untuk memberikan inspirasi kepada anggota organisasi dalam menganut nilai-nilai safety serta mewujudkannya dalam perilaku sehari-hari. Sistem manajemen sumber (seleksi, orientasi serta pengembangan serta sistem reword and punishment). Sistem safety yang mendorong orang untuk sulit berbuat salah, misalnya tidak melakukan prosedur jika pasien, keluarga, atau teman kerja belum menjawab pertanyaan identitas.

Pelaksanaan identifikasi dilakukan selama proses pelayanan (5). Verifikasi adalah kegiatan yang secara rutin harus dilakukan selama seting pelayanan (5), hal ini bisa berdampak pada timbulnya perasaan bahwa prosedur identifikasi sebagai tugas yang relatif tidak penting (4) baik bagi petugas maupun bagi pasien. Untuk itu diperlukan pendekatan untuk membudayakan nilai-nilai safety ini kepada seluruh staf termasuk staf medis agar nilai ini tidak hanya bertujuan untuk mengarahkan perilaku pelayanan saja namun menjadi basic assumptions yang sekaligus mendasari sikap, keyakinan serta nilai kerja (7) seluruh staf pendukung pelayanan.

Permasalahan yang masih dijumpai dalam pelaksanaan identifikasi di RS X adalah sebagian pasien dan keluarga belum terbiasa dengan prosedur verifikasi yang harus dilakukan selama setting pelayanan setiap akan melakukan prosedur pengobatan dan perawatan. Dalam hal ini kerjasama dengan pasien dan keluarga maupun orang terdekat pasien sangatlah diperlukan. Pasien, keluarga maupun orang terdekat harus diberikan penjelasan yang cukup tentang tujuan dari prosedur verifikasi dan risiko jika verifikasi tidak dilakukan. Hal ini perlu dilakukan untuk mengurangi resistensi pada pasien, keluarga serta orang terdekat terhadap pelaksanaan prosedur verifikasi (2). Dalam hal ini, staf harus memiliki kemampuan komunikasi yang baik agar tujuan komunikasi dapat berhasil. Kelebihan prosedur verifikasi seperti tersebut diatas dapat meningkatkan hubungan yang baik antar staf pelayanan dengan pasien, keluarga atau orang terdekat pasien (2). Lanoue E dan Still CJ berpendapat bahwa penggunaan teknologi barcode dalam sistem identifikasi dinilai memiliki tingkat akurasi lebih tinggi dan efektif karena verifikasi dilaksanakan melalui pencocokan simbol barcode dengan menggunakan canner (11). Kelemahan penggunaan metode barcode ini adalah komunikasi dengan pasien dan keluarga akan berjalan minimal. Mendidik pasien dan keluarga tentang risiko terjadi kesalahan identifikasi pasien merupakan pendekatan yang tepat untuk menjalin kerja sama dengan pasien dan keluarga dalam pelaksanaan proses identifikasi. Selanjutnya, petugas perlu mendorong pasien dan keluarga untuk aktif dalam proses identifikasi dengan meminta keluarga untuk menanyakan ulang apakah informasi yang diberikan memang benar untuk mereka, mengajukan pertanyaan atas perawatan serta pengobatan yang akan diberikan kepada mereka.

Perasaan sungkan atau tidak enak untuk melaporkan jika terjadi kesalahan identifikasi atau pelaksanaan identifikasi yang tidak sesuai dengan prosedur masih menjadi kendala. Hal ini memberikan gambaran bahwa nilai keterbukaan masih belum optimal pada staf. Masalah ini perlu mendapatkan perhatian karena adanya insiden yang tidak dilaporkan akan membawa dampak yang merugikan bagi rumah sakit untuk mendukung perbaikan sistem. Rendahnya pelaporan menyebabkan rumah sakit akan kehilangan kesempatan untuk belajar melalui kesalahan yang ada serta rumah sakit tidak mengetahui adanya peringatan potensial akan adanya bahaya yang dapat menyebabkan error (12). Salah satu strategi dalam merancang sistem keselamatan pasien adalah dengan memunculkan kesalahan sehingga dapat dilihat dan selanjutnya diambil tindakan untuk memperbaiki defek yang terjadi. Cara untuk memunculkan kesalahan adalah dengan membangun sistem pelaporan. Tujuan utama dari sistem pelaporan keselamatan pasien menurut WHO (13) adalah untuk belajar dari pengalaman dan monitoring kemajuan program. Karakteristik sistem pelaporan yang berhasil adalah (13): non punitive, confidential, independent, dianalisis oleh ahli, tepat waktu, berorientasi pada sistem serta responsive.

Tiga hal tersering yang menyebabkan terjadinya kesalahan identifikasi adalah kesalahan dalam penulisan dan administrasi, kesalahan dalam verifikasi dan masalah dalam komunikasi (13). Kesalahan penulisan dan administrasi meliputi kesalahan dalam labeling, kesalahan dalam pengisian data. Kesalahan penulisan identitas 
pasien pada rumah sakit tempat studi umumnya disebabkan oleh kesalahan petugas registrasi dalam memasukkan data identitas pasien dikarenakan pasien tidak membawa bukti identitas, sehingga informasi identitas hanya didasarkan atas informasi lisan dari pasien dan keluarga. Koreksi terhadap data identitas pasien dilakukan setelah pasien menunjukkan bukti identitas dengan bekerjasama petugas bagian electronic data processing (EDP). Meiliawati mencatat $58 \%$ petugas rekam medis tidak menginput data identitas pasien dengan benar (15). Contoh kesalahan dalam verifikasi misalnya: Prosedur verifikasi tidak ada dan prosedur verifikasi tidak dilaksanakan. Permasalahan terkait adanya hambatan dalam komunikasi misalnya: hambatan bahasa, kondisi pasien (gangguan kesadaran/mental) serta kegagalan dalam serah terima/alih tugas (hands off). Prinsip pencegahan kesalahan dalam identifikasi meliputi sebagai berikut (13): membuat kebijakan dalam rangka mengurangi risiko kesalahan identifikasi pasien, memberikan pelatihan dalam prosedur penilaian ulang (verifikasi) melalui orientasi dan pendidikan berkelanjutan, melibatkan secara aktif pasien dan keluarga dengan cara memberikan edukasi tentang risiko

\section{DAFTAR PUSTAKA}

1. Adisasmita W. Kesiapan Rumah Sakit Dalam Menghadapi Globalisasi. Jakarta: Universitas Indonesia; 2008.

2. World Health Organization. Patient Identification. Patient Safety Solutions. 2007; 1(2).

3. Setyowati D. Hubungan Kepemimpinan Head Ners dengan Penerapan Budaya Keselamatan Pasien Oleh Perawat Pelaksanan di RSUPN Dr. Cipto Mangun Kusumo Jakarta. [Tesis]. Universitas Indonesia, Jakarta. 2010.

4. Australian Commission on Safety and Quality in Health Care. Standard 5 Patient Identification and Procedure Matching. (Online) 2012. http://www.safetyandquality.gov.au/publications/sa fety-and-quality-improvement-guide-standard-5patient-identification-and-procedure-matchingoctober-2012/

5. Al-Qahtani AS and Missahel FM. Nurse's Role In Implementing Principles of Quality and Patient Safety. Riyadh: Executive Board Of the Health Ministers' Council For Cooperation Council States; 2003.

6. Prahasto ID. Medical Error di Rumah Sakit dan Upaya untuk Meminimalkan Risiko. Jurnal Manajemen Pelayanan Kesehatan. 2004; 7(1): 13-17.

7. Budhiharjdo A. Pentingnya Safety Culture di Rumah Sakit Upaya Meminimalkan Adverse Events. Jurnal Manajemen Bisnis. 2008; 1(1): 53-70.

8. Wirawan EA, Novitasari D, dan Wijayanti F. Hubungan jika terjadi kesalahan identitas dengan meminta pasien dan keluarga untuk bertanya dan mencocokkan pemeriksaan, tindakan medis, atau obat yang akan diberikan, memastikan bahwa setiap petugas yang terlibat bertanggung jawab dalam mengidentifikasi pasien dan berkomunikasi efektif sebelum setiap petugas melakukan tindakan.

Pelaksanaan sistem identifikasi pasien di rumah sakit tempat studi secara struktur sudah baik yang didasarkan pada visi, misi dan strategi dengan dilengkapi kebijakan, pedoman, panduan serta prosedur yang lengkap, namun kurang optimal pada supervisi terhadap pelaksanaan prosedur identifikasi terutama pada shift sore dan malam hari. Pembudayaan terhadap keselamatan pasien perlu terus ditingkatkan untuk meningkatkan kesadaran staf dalam mencatat dan melaporkan adanya insiden keselamatan termasuk ketidakpatuhan staf. Beberapa saran perbaikan yang bisa dilakukan dalam rangka lebih mengoptimalkan penerapan sistem identifikasi pasien adalah: mengoptimalkan peran supervisi keperawatan, pengoptimalan sistem pelaporan, meningkatkan budaya safety kepada seluruh staf termasuk pada staf medis.

antara Supervisi Kepala Ruang dengan Pendokumentasian Asuhan Keperawatan di Rumah Sakit Umum Daerah Ambarawa. Jurnal Manajemen Keperawatan. 2013; 1(1)

9. Nindyanto SIA, Sukesi N, dan Purnomo MAB. Pengaruh Supervisi Kepala Ruang terhadap Dokumentasi Asuhan Keperawatan di Ruang Rawat Inap RSDU Ungaran. Jurnal Ilmu Keperawatan dan Kebidanan. 2013; 1(4).

10. Rumampuk MVH, Budu, dan Nontji W. Peran Kepala Ruangan Melakukan Supervsi Perawat dengan Penerapan Patient Safety di Ruang Rawat Inap Rumah Sakit Gunung Maria Tomohon. [Tesis]. Universitas Hasanuddin, Makasar. 2011

11. Lanoue E and Still CJ. Patient Identification: Producing a Better Barcoded Wristband. (Online) 2008. h t t p : / / w w w.ps q h . com / may u n 08 / identification.html.

12. Lestari AP, Maidin A, dan Anggraeni R. Gambaran Budaya Keselamatan Pasien oleh Perawat dalam Melaksanakan Pelayanan di Instalasi Rawat Inap RSUP DR. Wahidin Sudirohusodo Tahun 2013. [Repository]. Universitas Hasanudin, Makasar. 2013.

13. Tim Rumah Sakit RK Charitas. Menuju Pelayanan Kesehatan yang Aman Kapita Seleksa Keselamatan Pasien di Rumah Sakit. Palembang: IKAPI-RS RK Charitas; 2009.

14. Meiliawati PL. Tinjauan Penerapan Identifikasi Pasien Dengan Benar di Unit Rekam Medis Rawat Inap Terkait Keselamatan Pasien di Rumah Sakit Pelabuhan Jakarta. [Tesis]. Universitas Esa Unggul, Jakarta. 2009. 